УДК 31

DOI 10.21661/r-552636

Ю.Н. Соловьева

Теоретико-методологические подходы к исследованию

социальной структуры: западные идеи в отечественной практике

Аннотация

Исследование социальной структуры общества предполагает отбор признаков, определяющих социальное расслоение. Многообразие этих признаков способствует появлению большого количества теоретико-методологических подходов. В статье исследуются наиболее значимые для изучения социальной структуры российского общества подходы, основанные на идеях представителей западной социологии: от классовых теорий до теорий социальной стратификации. В процессе трансформации общества меняется не только структура, но и фракторы, влияющие на неё, что обуславливает появление новых подходов для наиболее полного и точного анализа.

Ключевые слова: социальная структура общества, теоретико-методологические подходы, элементы социальной структуры.

\title{
Yu.N. Solovyova \\ Theoretical and Methodological Approaches to the Study of Social Structure: Western Ideas in Domestic Practice
}

\section{Abstract}

The study of the social structure of society involves the selection of features that determine social stratification. The variety of these features contributes to the emergence of a large number of theoretical and methodological approaches. The article examines the most significant approaches for studying the social structure of Russian society based on the ideas of representatives of Western sociology: from class theories to theories of social stratification. In the process of transformation of society, not only the structure changes, but also the factors influencing it, which leads to the emergence of new approaches for the most complete and accurate analysis.

Keywords: social structure of society, theoretical and methodological approaches, elements of social structure.

$\mathrm{M}$ ногообразие критериев, определяющих социальное расслоение общества, способствует обширному массиву теоретических и методологических подходов к изучению социальной структуры. Кроме того, в процессе трансформации общества меняется не только социальная структура, но и факторы, влияющие на неё, устанавливающие индикаторы для каждого слоя в структуре. Важным является факт частого несоответствия западных подходов отечественным реалиям, а, следовательно, и невозможность их использования для изучения российского социума. Указанные обстоятельства и ряд других определяют необходимость систематизировать теоретико-методологические подходы, способные наиболее адекватно и полно оценить социальную структуру современного российского общества, истолковать причины существующего неравенства между различными социальными группами, исключая возможные противоречия.
Противоречия эти заключаются, прежде всего, в природе исследований, а именно в различии целей каждого исследования, что, в свою очередь, порождает несовпадения в концептуальной и методологической основе.

Однако, несмотря на всё имеющееся разнообразие как теоретических, так и методологических подходов, наибольшее методологическое значение для исследования социальной структуры в России оказали лишь некоторые из них. В частности, особенности структуралистского и функционалистского подходов обусловили их применимость для анализа именно российского общества. Идеи структуралистского подхода к изучению общества были представлены в работах Огюста Конта. Основой данного подхода выступает плавное движение от определения каждого из элементов структуры к характеристике общей совокупности всех элементов. В противовес сущности структуралистского подхода выступает логика представителей функциона- 
листского подхода. Если структуралисты руководствовались принципом «от частного к общему», то функционалистский подход подразумевает, в первую очередь, рассмотрение системы в целом, а также функций, необходимых для её самовоспроизводства, и только потом изучение отдельных элементов исследуемой системы. Идею уделять внимание обществу как системе впервые высказал Толкот Парсонс. Главная сложность применения функционалистского подхода кроется в необходимости предварительного анализа общества и его функций, порождаемых многообразием элементов социальной структуры, и лишь потом непосредственным изучением самой структуры. Задача всестороннего рассмотрения общества и его функций сама по себе является достаточно трудоёмкой, и зачастую игнорируется в прикладных исследованиях, посвящённых социальной структуре. В отечественном опыте исключение составляет лишь работа Валерия Васильевича Радаева и Овсея Ирмовича Шкаратана, охарактеризовавших советское общество как этакратическую систему перед анализом его социальной структуры [2].

Несмотря на указанные различия в структуралистском и функционалистском подходах, их объединяет ряд методологических особенностей:

1. Ключевая позиция отводится отношениям внутри системы, а не факторам, расположенным во внешней среде, влияющим на систему, и взаимоотношениям системы со средой.

2. Главный фокус направлен на описание и систематизацию ячеек социального пространства, представляющих реальную социальную структуру общества и диктующих индивидам, занимающим эти ячейки, набор определённых социальных ролей, норм и моделей поведения. Однако, в недостаточной мере раскрывается сущность самих акторов, их индивидуальных особенностей, способствующих включению в ту или иную ячейку социальных пространств, а, следовательно, и изменению качественного содержания этих социальных пространств.

3. Оба подхода принимают во внимание не только элементы системы, но и их функции с той только разницей, что очерёдность и полнота их рассмотрения отличны друг от друга.

Именно эти методологические сходства обусловили со временем рассмотрение структуралистского и функционалистского подходов как взаимодополняющих. В результате возник единый структурно-функциональный подход, применяемый большинством социологов, занимающихся вопросами социальной структуры. Стоит отметить, что ведущим, однако, остаётся структурный подход в то время, как функционалистский выступает в качестве дополнительного.

Недостаток внимания к индивидуальным особенностям акторов в период трансформации модернистского общества (также индустриальное, капиталистическое) в постмодернистское (также постиндустриальное, информационное), характеризующееся, главным образом, ростом значимости индивидуализма, послужил основой для возникновения альтернативных подходов к определению социальной структуры. В частности, интеракционистский подход подразумевает дуальность сущности социальной структуры, где главенствующая роль отводится актору как элементу системы, не просто занимающему какую-либо социальную позицию, но и обладающему способностью воспроизводить эту систему и вносить изменения в неё. Разработка теоретико-методологических оснований исследования социальной структуры с позиции интеракционистского подхода велась Энтони Гидденсом [1].

Следует отметить, что применительно к российскому обществу, принимая во внимание этап его развития, наиболее перспективным для исследования социальной структуры представляется структурно-функциональный подход. Обусловлено это наличием ряда принципиально важных позиций, включаемых в указанный подход. В частности, структуралистский подход, вписываемый в рамки веберианской и неовеберианской традиции, во-первых, акцентирует внимание на системах социального действия, что способствует росту значимости индивидуального действия, жизнеспособности и перспектив социальной мобильности не только в условиях объективных экономических рамок определённых групп, но и от личного вклада самого индивида, его характерных способностей и имеющегося потенциала. Во-вторых, предпочтение в толковании экономического фактора социальной мобильности, выступающей одной из движущих сил изменения социальной структуры, в большей степени отдаётся не наличию собственности, а соотношению рыночных позиций групп в общем. Описание социальной структуры, имеющее в своей основе экономический признак, опирается, прежде всего, на жизненные шансы на рынке труда и потребления [3; 4; 12$]$.

Однако, возникает нехватка числа классических факторов социальной мобильности, представленных в рамках веберианского подхода. Поэтому необходимо включать элементы функционалистского подхода. Рассматривать, к примеру, идеи Т. Парсонса о статусе как вознаграждении за деятельность и, помимо этого, желательных качеств, а также ценности достижения как гарантии адаптации к динамичной общественной системе [9], применительно к трансформирующейся социальной структуре в России. Но стоит обратить внимание на один немаловажный факт - невозможность применения функционалистского подхода как методологической основы исследования российского общества в связи с одним из главных недостатков функционализма - отсутствием аргументированного обоснования процессов социальной мобильности. Процессы социальной мобильности, выступая предметом исследования с позиции вопроса факторов социальной структуры, обесценили эффективность применения нормативистского подхода Т. Парсонса и элементов функционалистского подхода в целом в условиях трансформации социума, когда формирование социальных групп порождает неясность в определении функций этих групп. 
Следует учесть, что в современной социологии сосуществуют два альтернативных подхода, один из которых включает индивидов в социальную систему, преобразуя их в один из её элементов, действующих в целом согласно занимаемой в этой системе позиции. Второй рассматривает индивидов как полноценных участников механизма функционирования, воспроизводства и изменения системы, характеризуя их действия как осознанные, рациональные и целенаправленные, в результате чего индивиды заполняют определённые ячейки соразмерно своему вкладу в общий процесс. Иными словами, в первом случае индивид воспринимается в качестве одной из составных частей структуры, во втором случае индивид - это один из главных факторов качественного развития струк туры. Опираясь на социологические исследования социальной структуры последних лет, можно сделать вывод, что всё чаще приоритет отдаётся второму подходу: ключевую позицию занимает не система, а человек в этой системе. В этом направлении разработка идей велась достаточно большим количеством социологов, временами с полярными точками зрения. Учитывая данное обстоятельство, целесообразным представляется упомянуть лишь тех из них, чьи работы послужили методологической основой в российских исследованиях.

В первую очередь, следует назвать имена Пьера Бурдьё и Мелвина Лестера Кона. Согласно П. Бурдьё, в современных обществах позиция и роль индивида в социальной структуре определяется набором ресурсов, выделяемым из всего многообразия типов так называемых капиталов. В этом смысле социологом выделяются экономический, культурный и символический капитал, определяемый всеми легитимными видами капитала и включающий в себя в некоторых случаях социальный капитал [5, с. 141]. Такой подход позволил П. Бурдьё рассматривать положение индивида в социальном пространстве в качестве производной от всех указанных видов капиталов в зависимости от суммарного объёма капитала, а также сообразно его структуре, под чем подразумевается соотношение различных видов капитала.

В отношении М.Л. Кона применительно к отечественной практике необходимо принимать во внимание его идеи о ценностных системах, различающихся от класса к классу, в частности, о факте соотношения «индивидуалистские/конформистские ориентации» в зависимости от социальных групп, занимаемых определённые статусные позиции [7, с. 14]. Социолог доказал тесную связь между ценностями и занимаемой в социальной структуре позицией. Согласно М.Л. Кону, индивидуалистические ориентации, то есть установки на достижение, присущи индивидам, обладающим более высоким социальным статусом и ощущающим себя полноправными членами благорасположенного к ним общества в то время, как конформистские ориентации или, иными словами, приспособленчество, характеризуют субъектов, которые занимают более низкие социальные позиции, находя себя менее компетентными членами равнодушного или враждебно настроенного к ним общества [8]. Относительно вопросов социальной мобильности М.Л. Кон отмечал, что уровень занимаемой социальной позиции зависит, прежде всего, от активности или пассивности самого человека, при этом однозначного ответа на вопрос о влиянии психологических качеств личности на направленность социальной мобильности не даётся. Однако, подчёркивается связь профессионального статуса с ценностями и ориентациями. Занимаемая позиция, с одной стороны, оказывает влияние на профессиональную установку на достижение, а с другой стороны - зависит от этой установки. А уже сама установка определяется психологическими качествами и обуславливает их. Это затрагивает не только ценности, но и активную направленность, фрустрацию, или, иными словами, неудачу, отчуждение и способность к восприятию и формированию идей.

Кроме вышеупомянутых авторов, проблемами индивида как рационального актора занимались Уильям Ллойд Уорнер, Джон Голдторп, а также Питер Таунсенд. Идеи этих социологов также оказали влияние на исследования социальной структуры в России. Так, У. Уорнер во главу угла ставил социокультурные факты, в частности, модели потребления и проведения свободного времени, значимость роли субъективных оценочных характеристик в определении социального статуса. Д. Голдтроп писал о различии стиля жизни и отличии в ценностях «белых и синих воротничков», в первую очередь, - о достаточной замкнутости социальных связей, приоритетом материальных мотивов, включающем в себя мотивацию трудовой деятельности, узконаправленные интересы и кругозор индивидов с низкой социальной позицией [6]. П. Таунсенд затронул проблему социального неравенства в отношении субъектов с низким социальным статусом, объяснив расслоение отсутствием возможностей для выстраивания продуктивных отношений и деятельности, поощряемых обществом, к которому относится индивид $[10 ; 11]$.

Обращая внимание на тенденции исследований социальной структуры современного российского общества, следует отметить, что в качестве приоритетного признака деления общества предпочтение отдаётся группе экономических факторов в том или ином их виде, будь то расслоение населения вследствие разного уровня благосостояния, неравенство по уровню жизни в целом, а также стратификация по доходу, обладанию собственностью или по их совокупности и др. Региональные исследования придерживаются логики общероссийских, основная их направленность - изучение определённого социального слоя или социальной группы в общей структуре с выявлением характерных особенностей и специфики формирования. Хабаровский край не является исключением. Объединяя разрозненные исследования различных авторов, можно сделать вывод, что в вычленение из социальной структуры одного из слоёв и его всестороннее изучение обеспечивает возможность более ясного понимания общей структуры, принципов её формирования, функций и факторов, оказывающих воздействие на эту структуру и способных изменять её.

Подавляющее большинство работ, однако, посвящено исследованию молодёжи, экономически активного 
населения и его видов, а также гражданского общества. Теоретико-методологическую основу данных исследований составляют идеи и труды ранее упоминавшихся зарубежных и отечественных социологов. В частности, широкое распространение получили структурно-функциональный, интеракционистский одноступенчатый подход, основанный на неравенстве жизненных шансов в сфере потребления вследствие разного уровня благосостояния, а также разновидности данных подходов, к исследованию социальной структуры общества в Хабаровском крае, основанные на работах западных социологов - К. Маркса, М. Вебера, П. Бурдьё, Э. Дюркгейма, Т. Парсонса, Э. Гидденса, а также ряда трудов отечественных авторов, внёсших наиболее значимый вклад в развитие вопросов социальной структуры - В.В. Радаева, О.И. Шкаратана, Т.И. Заславской, Ю.В. Арутюняна, В.А. Ядова. Подходы, базой для формирования которых явились идеи и труды вышеуказанных зарубежных и от- ечественных социологов, обеспечивают теоретическое обоснование проводимых исследований социальной структуры. Методологической основой выступают по большей части структурно-функциональный, конкретно-исторический, социологический и ресурсный подходы.

Подводя итог, стоит отметить, что при исследовании социальной структуры общества отдавая приоритет экономическим факторам расслоения населения по различным признакам, необходимо учитывать постоянно меняющиеся рыночные условия, выступающие в некоторых случаях ключевым показателем для определения статуса той или иной группы, ячейки или слоя. Имеет смысл опираться, прежде всего, не только на экономические индикаторы, но и на прочие показатели, способные адекватно охарактеризовать каждого отдельно взятого индивида,занимающего определённую статусную позицию в социальной структуре.

\section{Литература}

1. Гидденс Э. Социология / Э. Гидденс. - М.: Эдиториал УРСС, 1999.

2. Радаев В.В. Социальная стратификация / В.В. Радаев, О.И. Шкаратан. - М.: Аспект Пресс, 1996.

3. Радаев В.В. Экономическая социология / В.В. Радаев. - М.: Издательский дом ГУ-ВШЭ, 2008.

4. Шкаратан О.И. Социально-экономическое неравенство и его воспроизводство в России / О.И. Шкаратан. М.: ЗАО «ОЛМА Медиа Групп», 2009.

5. Bourdieu P. Distinction: A Social Critique of the Judgement of Taste / P. Bourdieu. - London: Routledge \& Kegan Paul, 1984.

6. Goldthorpe J. The Affluent Worker in the Class Structure / J. Goldthorpe, D. Lockwood, F. Bechhofer, J. Platt. England: Cambridge University Press, 1969.

7. Kohn M.L. Social Structure and Self-direction: A comparative analysis of the United States and Poland / M.L. Kohn, C. Schooler. - Oxford, England: Basil Blackwell, 1990.

8. Kohn M.L. Work and Personality. An inquiry into the impact of Social Stratification / M.L. Kohn, C. Schooler. USA: Ablex Pub. Corp., 1983.

9. Parsons T. A Revised Analytical Approach to the Theory of Social Stratification / T. Parsons. - USA: The Free Press, IL, 1953.

10. Townsend P. International Analysis of Poverty / P. Townsend. - London: Routledge \& Kegan Paul, 1993.

11. Townsend P. Poverty in the United Kingdome / P. Townsend. - Harmondsworth: Penguin, 1979.

12. Weber M. Economy and Society / M. Weber. - USA: Berkeley, CA, 1978.

\section{References}

1. Giddens, E. (1999). Sotsiologiia. M.: Editorial URSS.

2. Radaev, V. V., \& Shkaratan, O. I. (1996). Sotsial'naia stratifikatsiia. M.: Aspekt Press.

3. Radaev, V. V. (2008). Ekonomicheskaia sotsiologiia. M.: Izdatel'skii dom GUVShE.

4. Shkaratan, O. I. (2009). Sotsial'no-ekonomicheskoe neravenstvo i ego vosproizvodstvo v Rossii. M.: ZAO "OLMA Media Grupp".

5. Bourdieu, P. (1984). Distinction: A Social Critique of the Judgement of Taste. Kegan Paul.

6. Goldthorpe, J., Lockwood, D., Bechhofer, F., \& Platt, J. (1969). The Affluent Worker in the Class Structure. England: Cambridge University Press.

7. Kohn, M. L., \& Schooler, C. (1990). Social Structure and Self-direction: A comparative analysis of the United States and Poland. England: Basil Blackwell.

8. Kohn, M. L., \& Schooler, C. (1983). Work and Personality. An inquiry into the impact of Social Stratification. USA: Ablex Pub. Corp.

9. Parsons, T. (1953). A Revised Analytical Approach to the Theory of Social Stratification. IL.

10. Townsend, P. (1993). International Analysis of Poverty. Kegan Paul.

11. Townsend, P. (1979). Poverty in the United Kingdome. Harmondsworth: Penguin.

12. Weber, M. (1978). Economy and Society. CA. 